\title{
Ventilation Characterization of the Consumer Product Safety Commission Combustion Test Chamber Facility
}

W. Stuart Dols

September 1990

U. S. Department of Commerce Robert A. Mosbacher, Secretary National Institute of Standards and Technology John W. Lyons, Director Center for Building Technology Gaithersburg, MD 20899
Prepared for:

Consumer Product Safety Commission Directorate of Engineering Science

Washington, DC 20207 



\section{Ventilation Characterization of the Consumer Product Safety Commission Combustion Test Chamber Facility}

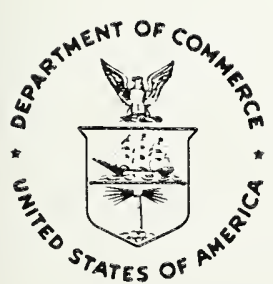

U. S. Department of Commerce National Institute of Standards and Technology Center for Building Technology Gaithersburg, MD 20899
Prepared for:

Consumer Product Safety Commission Directorate of Engineering Science Washington, DC 20207 



\section{ABSTRACT}

The Consumer Product Safety Commission (CPSC) is evaluating pollutant emissions from kerosene and methane heaters using a test chamber. Under an interagency agreement with CPSC, the Indoor Air Quality and Ventilation Group of the National Institute of Standards and Technology (NIST) measured the air exchange rate of the chamber under various ventilation system operating conditions, the extent of air mixing within the chamber, and the interior volume of the chamber. The air exchange rate of the chamber was determined using the tracer gas decay method with sulfur hexafluoride $\left(\mathrm{SF}_{6}\right)$ as the tracer gas. Carbon dioxide $\left(\mathrm{CO}_{2}\right)$ was also used as a tracer gas in order to verify the decay rates obtained with the $\mathrm{SF}_{6}$ system; however $\mathrm{CO}_{2}$ could not be used during combustion tests. The effect of pollutant monitoring systems and combustion devices on air exchange rates was also examined. Based on multi-point concentration measurements during decays, the extent of mixing within the chamber appeared to be adequate to employ the single-zone tracer gas decay method. The interior air volume of the chamber was determined using the constant injection tracer gas technique and yielded a volume very close to the volume based on the physical dimensions of the chamber. Recommendations for an air exchange rate measurement system for the chamber and modifications to be made in order to more effectively utilize the system are made.

KEY WORDS: air exchange rate, chambers, mixing, tracer gas techniques, ventilation 



\section{INTRODUCTION}

The Consumer Product Safety Commission (CPSC) combustion test chamber was designed to be a well-mixed single-zone facility to be used to determine the emission rate of pollutants produced by various combustion devices. Two important parameters in the determination of these pollutant emission rates are the air exchange rate during the combustion process and the interior air volume of the chamber. The tracer gas decay method is well suited for determining air exchange rates, but in order for this method to yield accurate results the tracer gas concentration within the chamber must be uniform. Thus, the first part of this project was to determine whether or not this condition existed; and if so, to determine the air exchange rate under various chamber operating conditions and in conjunction with the CPSC's combustion device characterization tests. Finally, the constant injection tracer gas technique was used to determine the chamber volume.

The test chamber is a commercially manufactured controlled environment room which has been modified by CPSC. It is located in a one story building at the CPSC test laboratory located in Gaithersburg, Maryland. The inner shell of the chamber is constructed from enamel coated aluminum and is approximately $3 \times 4 \times 2.75 \mathrm{~m}(10 \times 13 \times 9 \mathrm{ft})$. A schematic of the chamber and the main components of the ventilation system is shown in Figure 1. Air is drawn in from the room in which the chamber is located by the fan of a residential window unit air conditioner located on the top front of the chamber. The air is then ducted into an air conditioning space that is separated from the rest of the chamber by a dividing wall. Air then enters the main section of the chamber through an air-transfer grill in the dividing wall and is exhausted by a small centrifugal fan through a duct system to a fume hood located nearby in the building. Not shown in the diagram are four mixing fans, which are located in each corner of the room, a set of three large curtain-like water to air heat exchangers served by a constant temperature water bath that are used to maintain the temperature in the chamber, and a network of sampling tubes. 


\section{MEASUREMENT TECHNIQUES AND EQUIPMENT}

The degree of uniformity of tracer gas concentration within the chamber was determined by performing multi-point concentration measurements during tracer gas decay tests and comparing the concentrations at the different locations throughout the chamber. Having established tracer gas uniformity, air exchange rates were measured using the tracer gas decay technique [1]. Both sulfur hexafluoride $\left(\mathrm{SF}_{6}\right)$ and carbon dioxide $\left(\mathrm{CO}_{2}\right)$ were utilized as tracer gases. During heater testing, $\mathrm{CO}_{2}$ could not be used due to the fact that it is a product of combustion. Utilizing the tracer gas decay technique, the chamber air exchange rate was characterized with respect to the supply and exhaust flow rates of the chamber ventilation system. Finally the chamber volume was measured using an integral mass balance and constant injection tracer gas technique [2].

\section{Uniformity of Tracer Gas Concentration}

Tests were performed in order to verify the uniformity of tracer concentrations within the chamber. These tests consisted of injecting a small volume of $\mathrm{SF}_{6}$ into the chamber and then monitoring the concentration at nine locations within the chamber (points 1-9 in Figure 1). Each location was sampled every ten minutes and the concentration data for each location was fit by a curve based on equation 1 . These curves were then used to predict the concentration at each location at selected times. For each time the mean and standard deviation of the predicted concentrations were calculated.

\section{Air Exchange Rate Measurement}

The tracer decay procedure consisted of injecting a small volume of tracer gas into the supply air stream, allowing enough time for the tracer gas to come to a uniform concentration throughout the chamber, and then monitoring the decay in concentration over some period of time. If the tracer gas concentration is uniform and the air exchange rate is constant, then the decay of tracer gas concentration is governed by the following equation.

$$
C(t)=C_{0} e^{-I t}
$$

where: $\quad \mathrm{C}(\mathrm{t})=$ tracer gas concentration at time $\mathrm{t}$

$\mathrm{C}_{\mathrm{o}}=$ tracer gas concentration at time $\mathrm{t}=0$

I = air exchange rate, $\mathrm{h}^{-1}$

$\mathrm{t}=$ time, $\mathrm{h}$

By measuring the tracer gas concentration several times during the decay period, the air exchange 
rate, I, can be obtained by fitting the data to the logarithmic version of equation 1 using linear regression analysis. The air exchange rate in chamber volumes per unit time is given by the slope of the regression line. In the case of $\mathrm{SF}_{6}$, the background concentration is assumed to equal 0 . In the case of $\mathrm{CO}_{2}$, the background concentration is assumed to be constant and is simply subtracted from the measured chamber concentrations in equation 1.

The tracer gas was allowed to mix for approximately ten minutes after injection into the CPSC test chamber before the start of the air exchange rate calculation period. Concentrations in both the chamber exhaust and background were then monitored alternately every two minutes over a period of approximately one hour. $\mathrm{SF}_{6}$ concentrations were monitored using a gas chromatograph equipped with an electron capture detector and a microcomputer-based data acquisition system that automatically controlled the sampling sequence and recorded the data onto a floppy disk. The $\mathrm{CO}_{2}$ system was also automated and utilized an infrared absorption analyzer to measure the $\mathrm{CO}_{2}$ concentrations. Both systems are connected to a set of sampling pumps which provides continuous streams of air from up to 10 sample locations. This system is shown schematically in Figure 2. During the tracer decay tests only one location within the chamber was sampled, and the sample stream was rerouted back into the test chamber, thus eliminating the effect of the sample pump airflow rate on the air exchange rate of the chamber.

\section{Chamber Volume}

The interior volume of the chamber was measured using a constant injection tracer gas and an integral mass balance, utilizing $\mathrm{CO}_{2}$ as the tracer gas. The results were compared to the volume of the chamber determined from the physical dimensions of the chamber. The constant injection procedure employed the following single-zone mass balance equation, in volumetric terms, for the chamber as a single zone control volume.

$$
V \frac{d C(t)}{d t}=q_{b}(t) C_{b}(t)-q(t) C(t)+F(t)
$$

where: $\quad \mathrm{V}=$ interior air volume of the chamber

$C(t)=$ chamber tracer gas concentration at time $t$

$\mathrm{C}_{\mathrm{b}}(\mathrm{t})=$ background tracer gas concentration at time $\mathrm{t}$

$q(t)=$ volume flow rate of air out of the chamber at time $t$

$\mathrm{q}_{b}(\mathrm{t})=$ volume flow rate of air into the chamber at time $t$

$F(t)=$ volumetric generation rate of tracer gas within the chamber at time $t$

This equation indicates that at any instant in time the rate of accumulation of tracer within the zone, $\mathrm{VdC}(\mathrm{t}) / \mathrm{dt}$, is equal to the volume flow rate of tracer from the background into the chamber, $q_{b}(t) C_{b}(t)$, minus the volume flow rate of tracer out of the chamber, $q(t) C(t)$, plus the injection rate 
of tracer gas, $F(t)$, into the chamber. Application of the constant injection technique involved the injection of $\mathrm{CO}_{2}$ into the chamber at a constant flow rate and monitoring the buildup of tracer gas inside the chamber as well as the response in the supply air stream to the chamber; i.e. the background response. During the constant injection and buildup of $\mathrm{CO}_{2}$, several $\mathrm{SF}_{6}$ decay tests were also conducted to determine the air exchange rate of the chamber. Supply and exhaust airflow rates were monitored along with the chamber pressure in order to verify that the inlet and outlet flow rates were constant. Taking the inlet and outlet flow rates to be equal and constant during the time interval considered, and taking the volume flow rate $q(t)$ to be equal to IV, where I is the air exchange rate and $\mathrm{V}$ is the chamber volume, equation 2 can be integrated in order to obtain the following equation which was then solved for the chamber volume.

$$
V \Delta C_{12}=I V\left[\int_{t_{1}}^{t_{2}}\left[C_{b}(t)-C(t)\right] d t\right]+\int_{t_{1}}^{t_{2}} F(t) d t
$$

In this equation $\Delta C=C\left(t_{2}\right)-C\left(t_{1}\right)$, and the integral of $F(t)$ is the volume of tracer gas injected during the time interval being considered. The Trapezoidal Rule of numerical integration was used to determine the integral involving the concentrations from the tracer gas concentrations measured during the injection period. 


\section{RESULTS AND DISCUSSION}

\section{Uniformity of Tracer Gas Concentration}

In order to justify the use of tracer gas decay methods for the determination of air exchange rates in the chamber, it was necessary to show that the tracer gas concentration was uniform throughout the chamber during the tests. If the tracer gas concentration was not uniform, then the chamber could not be considered a single zone and the decay rate would not provide an accurate measure of the air exchange rate. Uniformity of tracer gas concentration is not only important for the decay experiments but also for the measurement of other pollutants in the chamber as well. However, achieving a uniform $\mathrm{SF}_{6}$ concentration after a discrete tracer gas injection does not necessarily imply that a pollutant with a different mode of generation will also be uniform. A test was also performed during the operation of a combustion device in order to ascertain the device's effects on the uniformity of tracer gas concentration in the chamber.

A set of three tracer gas uniformity tests was performed and the data are plotted in Figure 3. The first and third tests were performed without a combustion device operating in the chamber, and the second test was performed while a methane burner was operating on the floor in the center of the chamber. When these decay plots are considered in a qualitative manner, one can see that in each test the concentrations at all of the sample points generally fell on the same decay curve. This in itself implies a uniform tracer gas concentration within the chamber. But, in order to determine a quantitative measure of uniformity, the concentrations at each location were considered at the same times.

Due to the nature of the air sampling system, it was not possible to obtain the concentrations at each location simultaneously. Therefore, the concentrations at each location at the same times were determined as follows. Linear regressions were carried out for each location over the period of approximately one hour for each of the three tests to determine the parameters I and $\mathrm{C}_{\mathrm{O}}$ as given in equation 1. Concentrations were then calculated from these curves at ten minute intervals for each location. The average and standard deviation of the concentrations were then calculated for each desired instant in time (see Table 1).

Tracer gas concentrations appeared to be fairly uniform throughout the chamber. Standard deviations of concentrations ranged from $5 \%$ to $10 \%$ of the average concentration for each instant. Individual concentrations were generally within $5 \%$ of the average concentration for each time period. The concentrations at sample location 1 were consistently about $15 \%$ lower than the average for all locations. Location 3 in the first test and location 5 in the second test were approximately $10 \%$ lower than the average. Sample location 1 was located just in front of the air transfer grill between the conditioning space and the main chamber, therefore, the air at this point was being continuously diluted by the fresh air supply, which would explain the consistently lower concentrations at this point. Standard deviations based only on sample locations 2 through 10 
were between $4.5 \%$ and $7 \%$ of the average concentration for each instant. Sample points 3 and 5 were also located fairly close to the supply air stream and between the dividing wall and one of the curtain-like heat exchangers, which may contribute to the sometimes lower concentrations at these locations.

The combustion device had no detectable effect on the uniformity of tracer gas within the chamber. The uniformity of tracer gas concentration throughout the chamber may be attributed to the constant operation of the mixing fans. Locations 3 and 5 should be avoided as representative sample points due to their occasionally lower concentrations. For the tracer gas decay measurements, sample point 2 was selected as the representative location, which was inside the exhaust duct approximately $0.6 \mathrm{~m}(2 \mathrm{ft})$ downstream of the exhaust fan.

\section{Air Exchange Rate Measurements and Chamber Characterization}

The main objectives of the tracer decay testing performed by NIST was to determine the air exchange rate of the CPSC combustion test chamber under various ventilation system operating conditions, to determine the correlation between the air exchange rate and the chamber configuration, to insure that the tracer decay measurement can determine the air exchange rate independent of temperature effects and the presence other gases given off by various combustion devices, and to determine the hardware and software necessary to incorporate a tracer gas decay measurement system into the CPSC chamber system. A series of about thirty tests was performed, and the results are shown in Table 2 along with the chamber configuration during each test.

Air exchange rates are accurate to within $\pm 6 \%$ of the values given in Table 2 for the $\mathrm{SF}_{6}$ system and $\pm 3 \%$ for the $\mathrm{CO}_{2}$ system. In twelve of the tests $\mathrm{SF}_{6}$ and $\mathrm{CO}_{2}$ decay rates were measured simultaneously. The percent difference between the pairs of decay rates ranged from about $1 \%$ to $17 \%$, but were generally within $\pm 0.1 \mathrm{~h}^{-1}$ of each other. Chamber configuration is given by the ventilation flow settings, i.e. the supply and exhaust air velocities, the CPSC sample pump volume flow rates, and the pressure difference between the inside and outside of the chamber. All mixing fans were operating during every test.

The range of air exchange rates for the given set of chamber configurations based on both tracer decay systems was from 1.2 to $2.3 \mathrm{~h}^{-1}$. This includes two tests, 1 and 2 , which were performed before the chamber was operated at a negative pressure relative to the background environment (see Recommendations Section). Once a negative pressure of the chamber relative to the background was established, the supply air flow velocity was set at approximately $0.3 \mathrm{~m} / \mathrm{s}$ ( 60 $\mathrm{fpm}$ ) for the remainder of the tests and the air exchange rate was adjusted by varying the exhaust flow and turning on or off the CPSC sample pump system as indicated in Table 2. It should also be noted that during tests 16-18 there were nine NIST tracer decay system sample pumps drawing air out of the chamber from nine different locations at a combined airflow rate equivalent to approximately $0.3 \mathrm{~h}^{-1}$. To determine the relationship between the chamber configuration and air 
exchange rate, a plot of air exchange rate versus exhaust flow rate is given in Figure 4 for tests 3 through 10. There are two different data sets plotted on this graph; one shows the relationship while the CPSC's sample pumps were on and the other when they were off. Use of the CPSC's sample pumps tended to increase the air exchange rate by 0.1 to $0.3 \mathrm{~h}^{-1}$ based on the comparisons between tests 3 and 4, 7 and 8 , and 9 and 10. Based on a sample pump flow rate of $0.0015 \mathrm{~m}^{3} / \mathrm{s}$ $(3.18 \mathrm{cfm})$ and an approximate chamber volume of $24 \mathrm{~m}^{3}$, the increase in air exchange rate due to the pumps should have been approximately $0.2 \mathrm{~h}^{-1}$. Using this plot as a means for determining the chamber air exchange rate from the exhaust velocity may be a somewhat crude technique due to inaccuracies associated with the hot wire anemometer. One approach to obtaining an accurate measure of the air exchange rate based on air flow measurement is to negatively pressurize the chamber relative to the background, and make a direct and accurate measurement of the volume flow rate of air out of the chamber.

With regards to the ability of the two tracer decay systems to be utilized during combustion, only the $\mathrm{SF}_{6}$ system is applicable. This is due to the high emission rate of $\mathrm{CO}_{2}$ by the combustion process. If the decay rate was the same for a given chamber configuration, independent of whether or not combustion was occurring in the chamber, it would be possible to use the $\mathrm{CO}_{2}$ system to obtain the air exchange rate at the tail end of the combustion process based on the decay of the $\mathrm{CO}_{2}$ produced by combustion. However, this did not appear to be the case as indicated by tests 13-15 and 16-18. These two data sets each consisted of three consecutive decays; one decay during combustion and non-combustion decays before and after. In both cases the decay rate during the combustion test was higher than those without combustion by at least $0.15 \mathrm{~h}^{-1}$. This increase in air exchange rate could have been due either to the thermal decomposition of $\mathrm{SF}_{6}$ in the flame, or to the raising the air temperature inside the chamber by the methane burner causing a temperature induced pressure difference across the chamber envelope. It is somewhat doubtful that the former would be the case as indicated by the results of the mixing test. In other words, if a significant amount of $\mathrm{SF}_{6}$ were being depleted it would probably show up as a sink in the region of sample location 8 .

\section{Chamber Volume}

In order for CPSC to perform the necessary calculations regarding combustion pollutant emissions it was necessary to determine the internal air volume of the chamber. The volume was calculated using the constant injection tracer gas technique and solving an integral mass balance equation in volumetric terms. The calculated volume was then compared to the actual volume based on the inside dimensions of the chamber and the items contained within it.

Physical measurements of the chamber yielded a volume of approximately $24.2 \mathrm{~m}^{3}$ for the main section of the chamber and approximately $2 \mathrm{~m}^{3}$ for the conditioning space. Based on 
physical measurements and approximations, the volume of the other items in the chamber was determined to be a very small percentage of the entire volume (approximately $0.5 \%$ ), which was within the error of measurement itself and considered to be negligible.

The volume obtained using the constant injection technique was approximately $23.7 \mathrm{~m}^{3}$ $(+/-7 \%)$. This value is in very good agreement with the volume of the main section of the chamber as obtained from the physical dimensions. The relationship between the conditioning space and the main section of the chamber was not clear prior to these tests. It is now believed that the conditioning space is simply an extension of the supply air duct system and should not be considered a part of the control volume. 


\section{RECOMMENDATIONS}

The following recommendations are based on the results of the aforementioned tracer gas decay tests along with the previous experience obtained in the use of air exchange rate and pollutant monitoring systems in large scale test chambers by the Indoor Air Quality Group at NIST. Some of recommendations may require additional investigation regarding their significance, and others have already been implemented.

\section{Air Exchange Rate Measurement System}

In order for a tracer gas decay system to be incorporated with the CPSC combustion chamber system it should fulfill the following basic criteria: it should be able to determine the air exchange rate accurately, it should not affect or be affected by the CPSC pollutant monitoring system, and it should be able to determine the air exchange rate while various combustion devices are being operated inside the test chamber. Based on the tests which were performed by NIST, the $\mathrm{SF}_{6}{ }^{-}$ based system used in these tests can fulfill all of these requirements. While the $\mathrm{CO}_{2}$-based system performed well in the absence of combustion, it can not be used during the combustion process.

While a tracer gas decay system is a very efficient and effective means of determining the air exchange rate of the chamber, it is not the only means. Given the chamber volume, accurate measurements of the net flow rate supplied by the mechanical ventilation system would also suffice. However, some changes would have to be made in the current mechanical ventilation system airflow monitoring system in order to accurately and reliably apply this technique. Reliable and accurate volume flow monitoring devices should be properly located in the intake and supply ducts of the chambers. This involves providing the proper length of straight duct both upstream and downstream of the measurement points. Ideally, the chamber envelope would be airtight, but this is generally not feasible. A more practical approach would be to keep the inside of the chamber at a negative pressure relative to the outside of the chamber (i.e. the background), which would ensure that all the air leaving the chamber will exit through the chamber exhaust system, and measure the exhaust airflow rate.

It is recommended that the $\mathrm{SF}_{6}$ tracer gas decay system be incorporated into the CPSC combustion chamber system as the most practical means of determining the air exchange rate including times when the combustion devices are being used. The tracer gas decay method is a well developed means of determining air exchange rate. No change in the system used by NIST would be required for the incorporation of this system into the CPSC system. However, a few minor modifications could be made at the discretion of CPSC, such as, replacing the sample pumps which are currently used with pumps having a lower volume flow rate and customizing the data acquisition and control software for the application of automated tracer gas injection and decay rate monitoring to this specific test procedure. 


\section{Chamber Design and Test Procedure Modifications}

Some general modifications in chamber design were suggested in order to make the chamber more suitable as a pollutant emissions test chamber. A list of suggested design modifications follows along with an explanation for each modification. Those with an asterik $\left({ }^{*}\right)$ have already been implemented.

1. ${ }^{*}$ Negatively pressurize the chamber relative to the background, thus ensuring that all air leaving the chamber does so via the exhaust air system. This is necessary especially with the background air serving as the chamber supply air. This background air would become contaminated by pollutants or tracer gas from the chamber if the were positively pressurized relative to the background. A background with elevated levels of pollutants could complicate measurements in two ways: exposure of measurement devices to elevated levels can cause erroneous readings by some instruments, and reentrainment of exhausted pollutants into the test chamber could complicate the application of mass balance models.

2. Eliminate the conditioning space by removing the separating wall. The space conditioning duct may be acting as a separate zone. Once this step has been taken, the mixing test and the constant tracer gas injection test to determine the chamber volume should be repeated.

3. Eliminate or restrict activities in the background zone which tend to interfere with the tests being performed in the chamber, or isolate the chamber background from outside interference. During the measurement of $\mathrm{CO}_{2}$, the presence of people in the background zone will increase the background levels of $\mathrm{CO}_{2}$ thereby introducing a source of $\mathrm{CO}_{2}$ other than the products of combustion or tracer gas and possibly invalidating the mass balance equations used for analysis.

4. ${ }^{*}$ Replace or cover CPSC sample tubing with a material which is known not to interfere with the pollutants being tested for. Some tubing materials can react with, absorb and/or desorb, or even emit certain chemicals. CPSC either wrapped its sample tubing with aluminum tape or encased it inside aluminum conduits.

5. Incorporate an air sampling system into the pollutant monitoring system which would enable the continuous sampling of the chamber and background concentrations instead of relying on background readings taken before and after test runs. Readings taken before and after the test run give no indication of background levels during the tests, when it is 
most important.

6. Install a supply fan which runs independently of the supply air conditioning load, or omit the supply fan altogether and use only an exhaust fan as a means of forced ventilation. This would help to guarantee a negatively pressurized chamber relative to the background and a constant ventilation rate. The current supply fan is that of a residential window unit air conditioner and appears to vary based on the cooling load.

7. Control temperature using conventional methods (e.g. heat pump) as opposed to the curtain-like heat exchangers which could obstruct the flow of air within the chamber. 


\section{REFERENCES}

[1] ASTM, 1983, "Standard Test Method for Determining Air Leakage Rate by Tracer Dilution," E741, American Society for Testing and Materials, Philadelphia, PA.

[2] Axley, J., A.K. Persily, 1988, "Integral Mass Balances and Pulse Injection Tracer Techniques," NISTIR 88-3855, National Institute of Standards and Technology, Gaithersburg, MD.

\section{ACKNOWLEDGEMENTS}

I would like to thank Al Martin, Larry Mulligan and the IAQ staff of the Consumer Product Safety Commission for their continuous efforts in making the performance of these experiments proceed as smoothly as possible. I would also like to thank Andy Persily and Richard Grot of NIST for their invaluable counsel and support on all aspects of this project. 


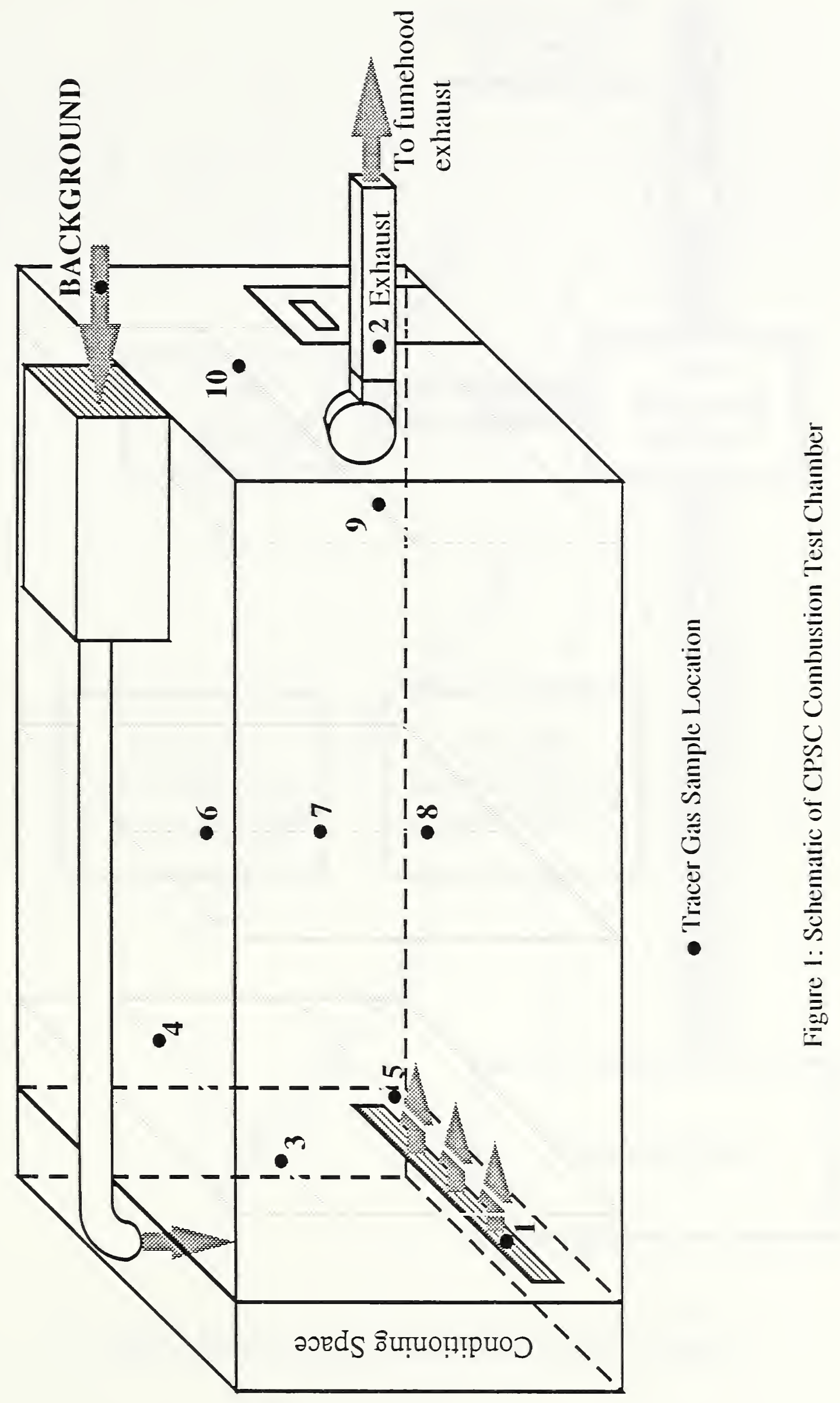




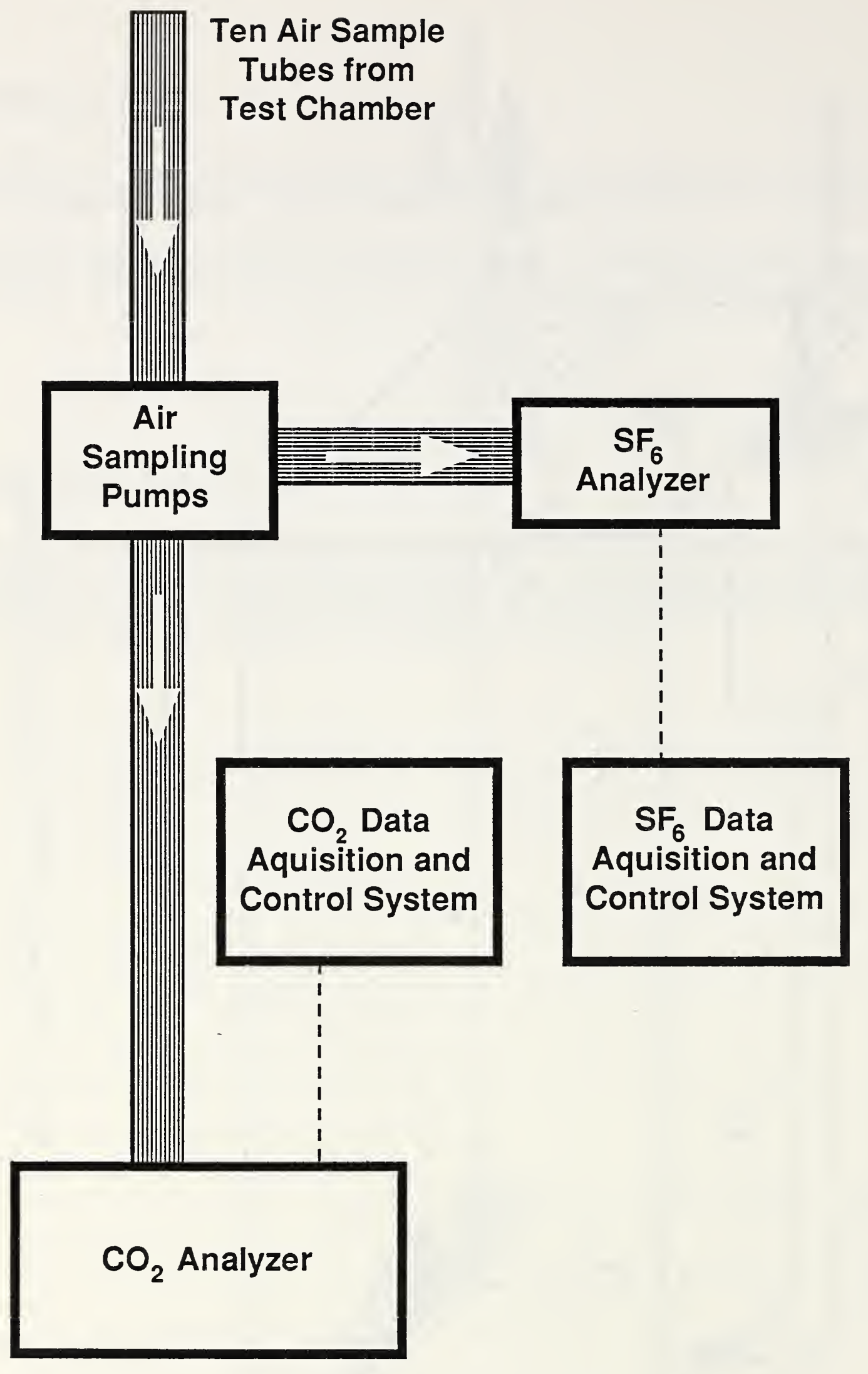

Figure 2: Schematic of $\mathrm{SF}_{6}$ and $\mathrm{CO}_{2}$ Measurement Systems 


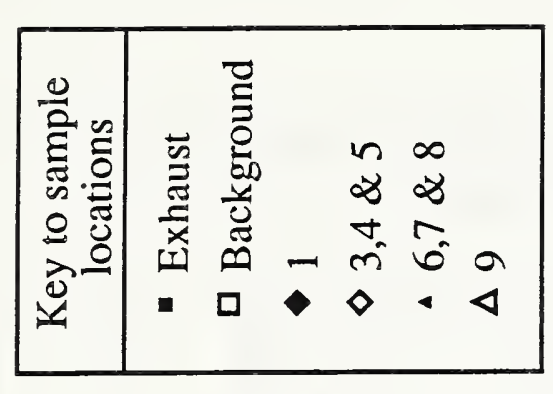

$T \stackrel{8}{\stackrel{8}{\infty}}$

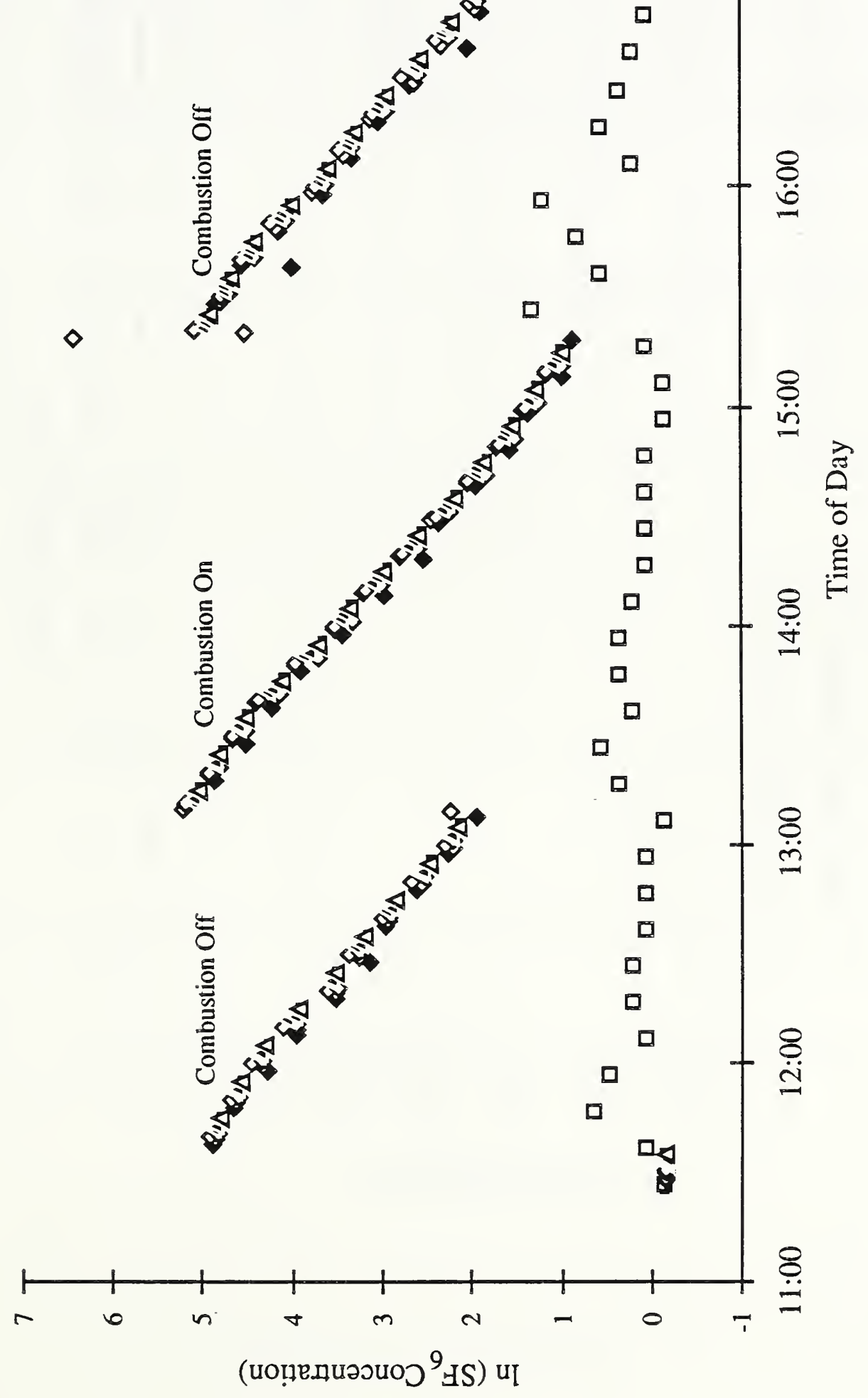

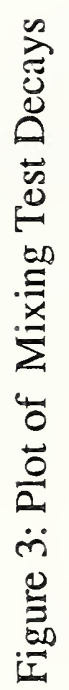




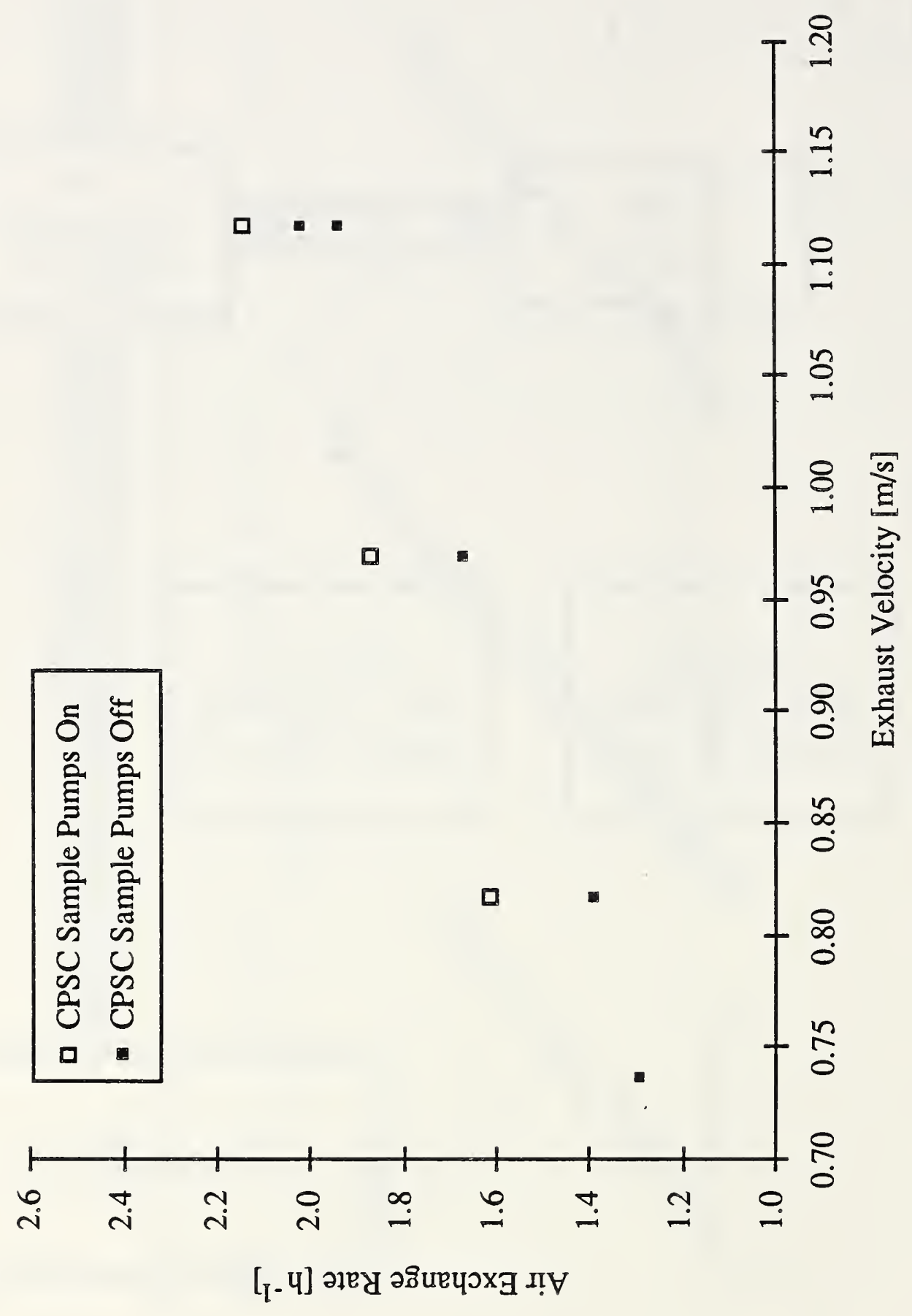

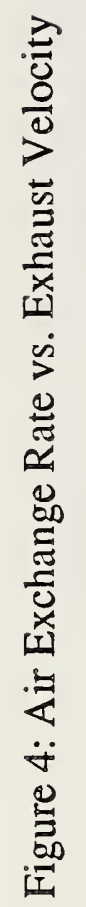




\begin{tabular}{|c|c|c|c|c|c|c|c|c|c|c|c|c|}
\hline \multirow{3}{*}{ Time } & \multicolumn{9}{|c|}{ SF6 Concentrations (ppb) Based on Linear Regression } & \multirow{3}{*}{ AVG } & \multirow{3}{*}{ STD DEV } & \multirow{3}{*}{$\%$ STD DEV } \\
\hline & \multicolumn{9}{|c|}{ Sample Location } & & & \\
\hline & 1 & 2 & 3 & 4 & 5 & 6 & 7 & 8 & 9 & & & \\
\hline $11: 56$ & 75.0 & 97.9 & 81.8 & 96.0 & 87.6 & 99.4 & 98.4 & 96.2 & 99.0 & 92.4 & 8.3 & 9.0 \\
\hline $12: 06$ & 53.8 & 68.5 & 57.8 & 67.3 & 61.6 & 69.5 & 68.9 & 67.2 & 69.3 & 64.9 & 5.4 & 8.4 \\
\hline $12: 16$ & 38.6 & 47.9 & 40.8 & 47.1 & 43.3 & 48.6 & 48.2 & 46.9 & 48.5 & 45.5 & 3.5 & 7.7 \\
\hline $12: 26$ & 27.7 & 33.5 & 28.8 & 33.0 & 30.4 & 33.9 & 33.8 & 32.8 & 33.9 & 32.0 & 2.3 & 7.1 \\
\hline $12: 36$ & 19.9 & 23.5 & 20.3 & 23.1 & 21.4 & 23.7 & 23.6 & 22.9 & 23.8 & 22.5 & 1.4 & 6.4 \\
\hline $12: 46$ & 14.2 & 16.4 & 14.3 & 16.2 & 15.0 & 16.6 & 16.6 & 16.0 & 16.6 & 15.8 & 0.9 & 5.8 \\
\hline $12: 56$ & 10.2 & 11.5 & 10.1 & 11.4 & 10.6 & 11.6 & 11.6 & 11.2 & 11.6 & 11.1 & 0.6 & 5.2 \\
\hline $13: 26$ & 104.0 & 122.8 & 123.6 & 128.5 & 109.0 & 128.4 & 129.7 & 124.7 & 127.0 & 122.0 & 8.6 & 7.1 \\
\hline $13: 36$ & 70.9 & 84.1 & 84.6 & 87.5 & 74.4 & 87.5 & 88.0 & 84.8 & 86.4 & 83.1 & 5.8 & 7.0 \\
\hline $13: 46$ & 48.3 & 57.6 & 57.8 & 59.5 & 50.8 & 59.6 & 59.7 & 57.7 & 58.7 & 56.7 & 3.9 & 6.9 \\
\hline $13: 56$ & 33.0 & 39.5 & 39.6 & 40.5 & 34.7 & 40.6 & 40.6 & 39.2 & 40.0 & 38.6 & 2.6 & 6.8 \\
\hline $14: 06$ & 22.5 & 27.1 & 27.1 & 27.6 & 23.7 & 27.7 & 27.5 & 26.7 & 27.2 & 26.3 & 1.8 & 6.8 \\
\hline $14: 16$ & 15.3 & 18.5 & 18.5 & 18.8 & 16.2 & 18.8 & 18.7 & 18.1 & 18.5 & 17.9 & 1.2 & 6.7 \\
\hline $14: 26$ & 10.4 & 12.7 & 12.7 & 12.8 & 11.0 & 12.8 & 12.7 & 12.3 & 12.6 & 12.2 & 0.8 & 6.7 \\
\hline $15: 36$ & 76.1 & 107.6 & 102.4 & 106.3 & 95.3 & 108.9 & 109.5 & 105.0 & 108.7 & 102.2 & 10.1 & 9.9 \\
\hline $15: 46$ & 54.5 & 75.3 & 70.8 & 74.5 & 66.6 & 75.9 & 76.2 & 73.3 & 75.8 & 71.4 & 6.7 & 9.3 \\
\hline $15: 56$ & 39.0 & 52.6 & 49.0 & 52.1 & 46.6 & 52.9 & 53.1 & 51.2 & 52.9 & 49.9 & 4.4 & 8.8 \\
\hline $16: 06$ & 27.9 & 36.8 & 33.9 & 36.5 & 32.6 & 36.9 & 37.0 & 35.7 & 36.9 & 34.9 & 2.9 & 8.2 \\
\hline $16: 16$ & 20.0 & 25.7 & 23.4 & 25.6 & 22.8 & 25.7 & 25.8 & 24.9 & 25.7 & 24.4 & 1.9 & 7.7 \\
\hline $16: 26$ & 14.3 & 18.0 & 16.2 & 17.9 & 15.9 & 17.9 & 17.9 & 17.4 & 17.9 & 17.1 & 1.2 & 7.2 \\
\hline $16: 36$ & 10.2 & 12.6 & 11.2 & 12.6 & 11.2 & 12.5 & 12.5 & 12.1 & 12.5 & 11.9 & 0.8 & 6.7 \\
\hline
\end{tabular}

\begin{tabular}{|c|c|c|c|c|c|c|c|c|c|}
\hline & \multicolumn{10}{|c|}{ Percent Difference From Average Concentration } \\
\cline { 2 - 10 } & 1 & 2 & 3 & 4 & 5 & 6 & 7 & 8 & 9 \\
\hline $11: 56$ & -19 & 6 & -11 & 4 & -5 & 8 & 6 & 4 & 7 \\
$12: 06$ & -17 & 6 & -11 & 4 & -5 & 7 & 6 & 4 & 7 \\
$12: 16$ & -15 & 5 & -10 & 4 & -5 & 7 & 6 & 3 & 6 \\
$12: 26$ & -13 & 5 & -10 & 3 & -5 & 6 & 6 & 2 & 6 \\
$12: 36$ & -12 & 4 & -10 & 3 & -5 & 6 & 5 & 2 & 6 \\
$12: 46$ & -10 & 4 & -9 & 3 & -5 & 5 & 5 & 1 & 5 \\
$12: 56$ & -8 & 4 & -9 & 3 & -5 & 5 & 5 & 1 & 5 \\
\hline
\end{tabular}

\begin{tabular}{|l|l|l|l|l|l|l|l|l|l|}
\hline $13: 26$ & -15 & 1 & 1 & 5 & -11 & 5 & 6 & 2 & 4 \\
$13: 36$ & -15 & 1 & 2 & 5 & -10 & 5 & 6 & 2 & 4 \\
$13: 46$ & -15 & 2 & 2 & 5 & -10 & 5 & 5 & 2 & 4 \\
$13: 56$ & -15 & 2 & 2 & 5 & -10 & 5 & 5 & 2 & 3 \\
$14: 06$ & -15 & 3 & 3 & 5 & -10 & 5 & 5 & 1 & 3 \\
$14: 16$ & -15 & 3 & 3 & 5 & -10 & 5 & 4 & 1 & 3 \\
$14: 26$ & -15 & 4 & 4 & 5 & -10 & 5 & 4 & 1 & 3 \\
\hline
\end{tabular}

\begin{tabular}{|l|l|l|l|l|l|l|l|l|l|}
\hline $15: 36$ & -26 & 5 & 0 & 4 & -7 & 7 & 7 & 3 & 6 \\
$15: 46$ & -24 & 5 & -1 & 4 & -7 & 6 & 7 & 3 & 6 \\
$15: 56$ & -22 & 5 & -2 & 4 & -7 & 6 & 6 & 2 & 6 \\
$16: 06$ & -20 & 5 & -3 & 5 & -7 & 6 & 6 & 2 & 6 \\
$16: 16$ & -18 & 5 & -4 & 5 & -7 & 5 & 6 & 2 & 5 \\
$16: 26$ & -16 & 5 & -5 & 5 & -7 & 5 & 5 & 2 & 5 \\
$16: 36$ & -14 & 5 & -6 & 5 & -6 & 5 & 5 & 2 & 5 \\
\hline
\end{tabular}

Table 1: Mixing Test Results 


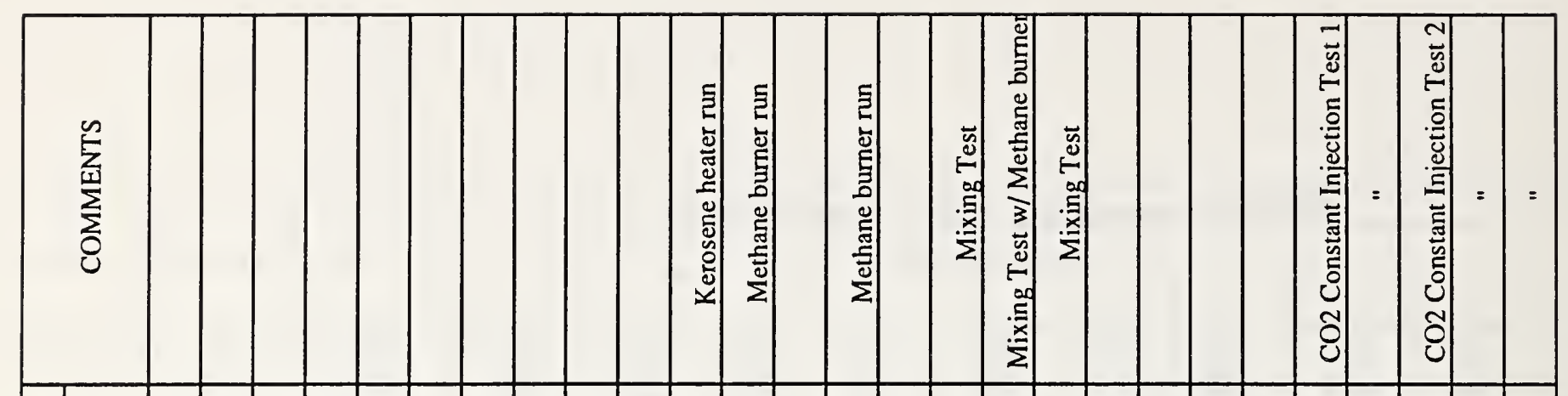

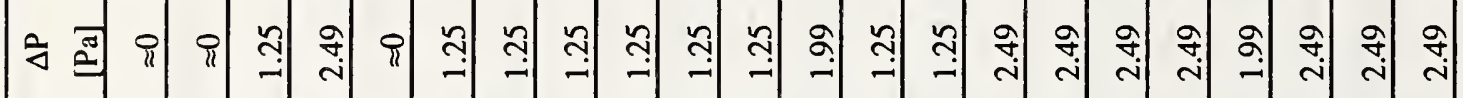

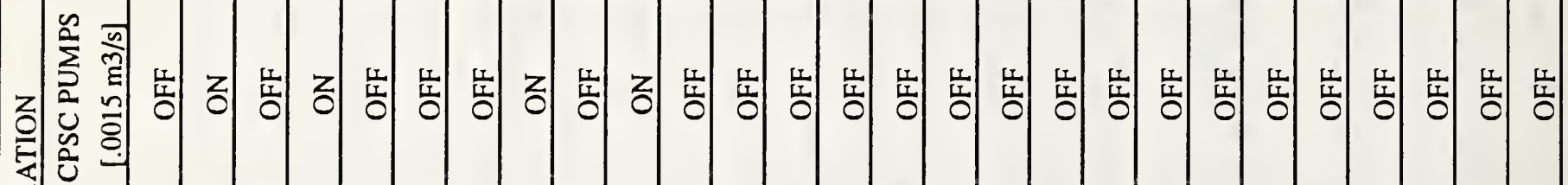

窇

親

离

$\stackrel{\Sigma}{\frac{1}{x}}$

穿

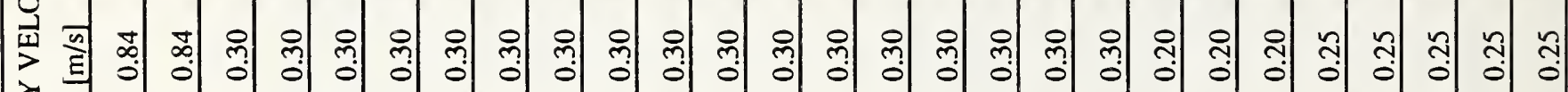
$>$

育

రิ

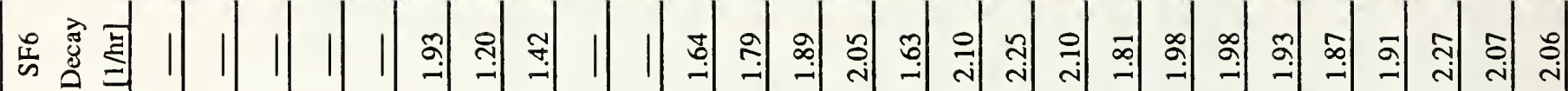

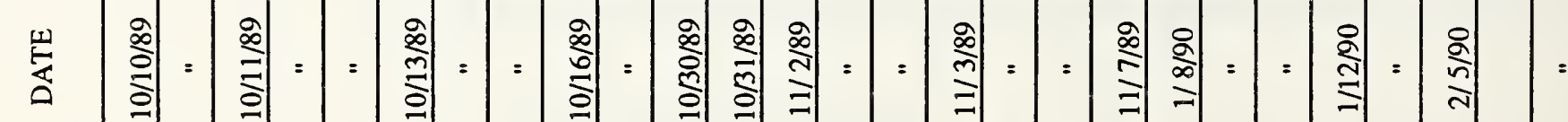

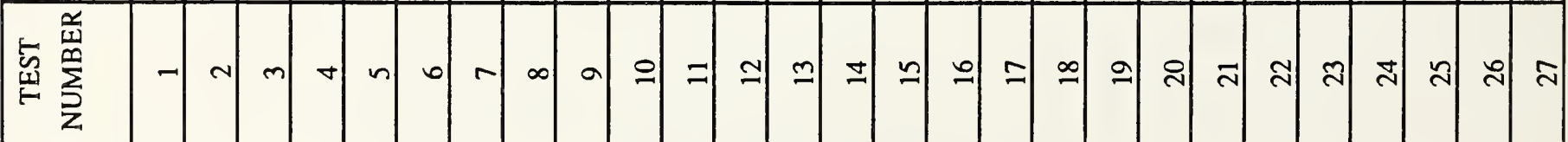




\begin{tabular}{|c|c|c|}
\hline \multirow[t]{4}{*}{$\begin{array}{l}\text { NIST-114A } \\
\text { (REV. 3-90) }\end{array}$} & \multirow{4}{*}{$\begin{array}{l}\text { U.S. DEPARTMENT OF COMMERCE } \\
\text { NATIONAL INSTITUTE OF STANDARDS AND TECHNOLOGY } \\
\text { BIBLIOGRAPHIC DATA SHEET }\end{array}$} & $\begin{array}{l}\text { 1. PUBUCATION OR REPORT NUMBER } \\
\text { NISTIR }-4415\end{array}$ \\
\hline & & PERFORMING ORGANIZATION REPORT NUMBER \\
\hline & & 3. PUBLCATION DATE \\
\hline & & September 1990 \\
\hline
\end{tabular}

4. TITLE AND SUBTITLE

Ventilation Characterization of the Consumer Product Safety Comission Combustion Test Chamber Facility

5. AUTHOR(S)

W. Stuart Dols

6. PERFORMINO ORGANIZATION (IF JOINT OR OTHER THAN NIST, SEE INSTRUCTIONS)

U.S. DEPARTMENT OF COMMERCE

NATIONAL INSTITUTE OF STANDARDS AND TECHNOLOGY

GATHERSBURG, MD 20890

7. CONTRACT/GRANT NUMBER

8. TYPE OE REPORT AND PERIOD COVERED

9. SPONSORING ORGANIZATION NAME AND COMPLETE ADDRESS (STREET, CITY, STATE, ZP)

U.S. Consumer Product Safety Commission

Washington, DL 20207

10. SUPPLEMENTARY NOTES

11. ABSTRACT (A ZOO-WORD OR LESS FACTUAL SUMMARY OF MOST SIGNIFICANT INFORMATION. IF DOCUMENT INCLUDES A SIGNIFICANT BIBLIOGRAPHY OR UTERATURE SURVEY, MENTION IT HERE)

The Consumer Product Safety Commission (CPSC) is evaluating pollutant emissions from kerosene and methane heaters using a test chamber. Under an interagency agreement with CPSC, the Indoor Air Quality and Ventilation Group of the National Institute of Standards and Technology (NIST) measured the air exchange rate of the chamber under various ventilation system operating conditions, the extent of air mixing within the chamber, and the interior volume of the chamber. The air exchange rate of the chamber was determined using the tracer gas decay method with sulfur hexafluoride $\left(\mathrm{SF}_{6}\right)$ as the tracer gas. Carbon dioxide $\left(\mathrm{CO}_{2}\right)$ was also used as a tracer gas in order to verify the decay rates obtained with the $\mathrm{SF}_{6}$ system; however $\mathrm{CO}_{2}$ could not be used during combustion tests. The effect of pollutant monitoring systems and combustion devices on air exchange rates was also examined. Based on multi-point concentration measurements during decays, the extent of mixing within the chamber appeared to be adequate to employ the single-zone tracer gas decay method. The interior air volume of the chamber was determined using the constant injection tracer gas technique and yielded a volume very close to the volume based on the physical dimensions of the chamber. Recommendations for an air exchange rate measurement system for the chamber and modifications to be made in order to more effectively utilize the system are made.

12. KEY WORDS (6 TO 12 ENTRIES; ALPHABETICAL ORDER; CAPITALZE ONLY PROPER MAMES; AND SEPARATE KEY WORDS BY SEMICOLONS) air exchange rate; chambers; mixing; tracer gas techniques; ventilation 


